\title{
Steering System of Go-Kart
}

\author{
Mohd Anwar', Ashraf Shaik², Mohd Sohail ${ }^{3}$ \\ Assistant Professor, Mechanical Department, Lords Institute of Engg \& Tech, Hyderabad, India ${ }^{1}$ \\ Associate Professor, Mechanical Department, Lords Institute of Engg \& Tech, Hyderabad, India ${ }^{2}$ \\ Student, Mechanical Department, Lords Institute of Engg \& Tech, Hyderabad, India ${ }^{3}$
}

\begin{abstract}
Mechanical linkages steering systems are commonly used due to their simplicity in construction and compactness. The main purpose of this paper is to design and manufacture manual mechanical linkages steering system according to the requirement of the vehicle for better maneuverability. Quantities like turning circle radius, steering ratio, steering effort, etc. are inter-dependent on each other and therefore there are different design consideration according to the type of vehicle. The comparison of result is shown using tables which will help to design an effective steering for the vehicle. A virtual mechanical linkages assembly can be created using software like SOLIDWORKS.
\end{abstract}

Keywords: Steering ratio, steering wheel torque, inner wheel and outer wheel angle, Mechanical linkages steering.

\section{INTRODUCTION}

The steering system is of important part of the dynamic design of any automobile to facilitate a smooth change of directions and make use of the tires ability to generate lateral forces to the highest extent. A racing driver's sensory inputs supply visual, tactile, and inertial information used in developing a "feel" for car handling and performance. This feedback is necessary in enabling the driver to extract maximum performance from the race car. Hence the steering is an important feedback mechanism giving the driver information on stability and directional control. The control of an automobile is done by means of a steering system which provides directional changes to the moving automobile. The intention of Ackermann geometry is to prevent the tyres from slipping outwards when the wheels follows around a curve while taking a turn. The solution for this is that all wheels to have their axles settled as radii of circles with a common centre point. Since the rear wheels are fixed, this centre point must lie on a line extended from the rear axle. So we need to intersect the front axle to this line at the common centre point. While steering, the inner wheel angle is greater than outer wheel angle. So for obtaining different results we need to vary the parameters in order to obtain desired steering geometry

\section{II.DESIGN METHODOLOGY}

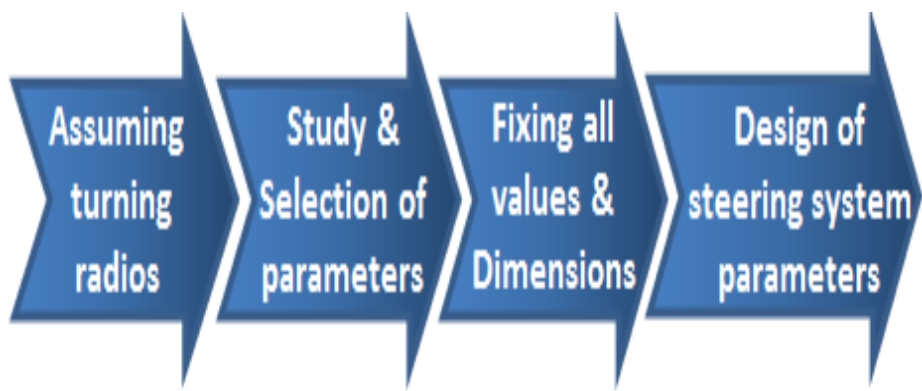

Fig. 1. Design methodology of steering system

\section{STEERING SYSTEM}

\section{Ackermann principal of steering}

To solve the problem of wheels on the inside and outside of a turn needing to trace out circles of different radius, Ackermann principle of steering is used. Assumptions

- $100 \%$ Ackermann steering geometry.

- Maximum road bank angle is $20^{\circ}$.

- Optimum kingpin inclination angle range is $4^{\circ}$ to $8^{\circ}$.

- Front to rear weight ratio is 40:60.

- Taking acceleration due to gravity as $10 \mathrm{~m} / \mathrm{s}^{\wedge} 2$ 
A. Goals

- To enable smooth and stable maneuvering of the vehicle.

- To provide feedback to the drive.

- To optimize the steering effort

- Provide adjustability for parameters such as caster angle and toe.

- To select and implement the best mechanism that suits the purpose

B. Steering Geometry

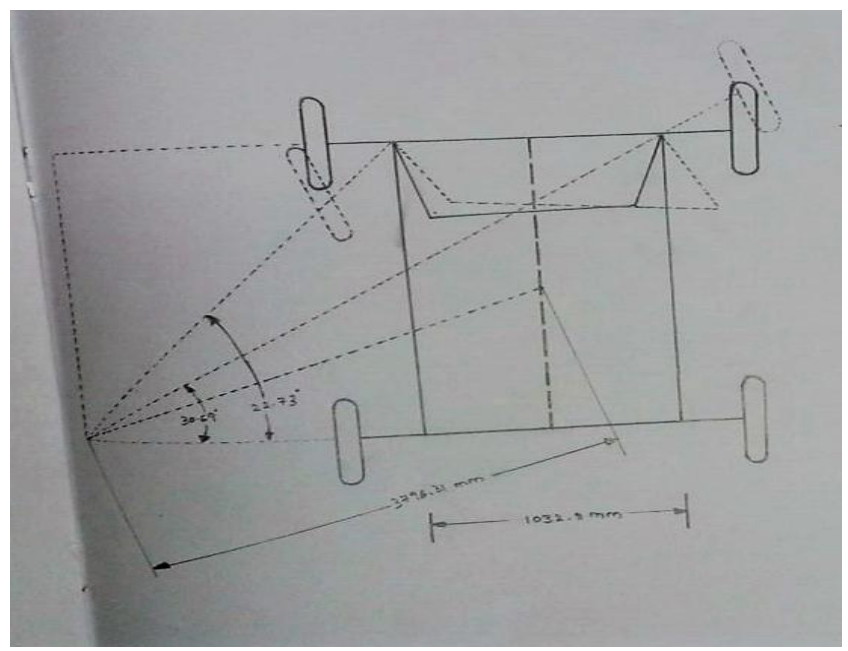

Fig. 2. Steering design

1) Selection: Ackerman steering Geometry with mechanical linkages mechanism this geometry makes the inside wheel steer to a greater angle than the outside wheel and all the wheels roll about a common turn center. Since the cornering speeds are small, Ackerman geometry is an ideal choice. The mechanism was simulated in solid works software and after several trials the following configuration was obtained which satisfied Ackerman condition with minimal error.

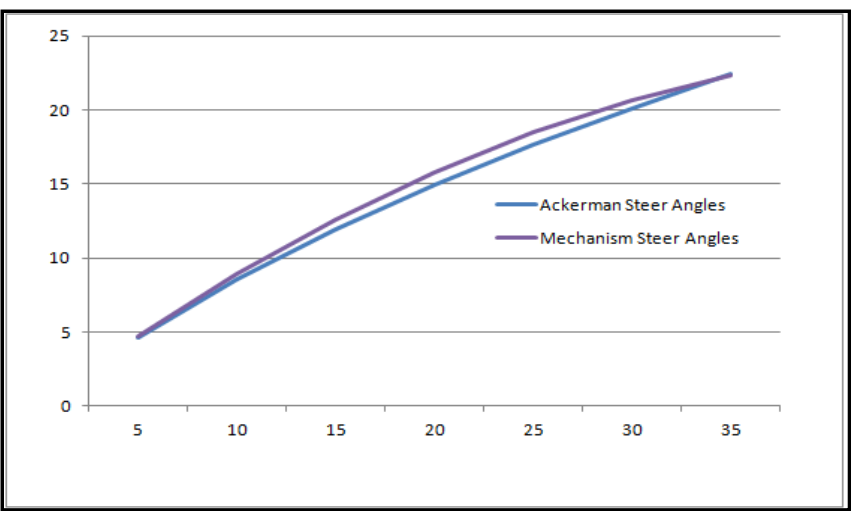

Fig.3. Steering Mechanism

The above graph is a comparison of the angles obtained by the formula theoretically and the angle obtained by simulation of the geometry.

The inner angle is fixed to a value within the range of angles which satisfy the equation and the outer angle is measured.

C. Considerations

- Camber: The camber angle is set to zero degree as there is no suspension system to provide dynamic camber during cornering.

- Caster: It is the angle made by the kingpin with the vertical measured from the side of the tire. Positive caster angle, although increases steering effort, is necessary to obtain self-aligning torque and also enable the inside rear wheel to lift during cornering since the kart does not have a differential at the rear axle 
- Kingpin Inclination: Due to the geometry of the stub axle the King pin offset is high, which demands large kingpin inclination to minimize scrub radius which is not feasible. Hence it is set to 0 (zero) degree.

\section{CALCULATIONS}

A. Approach

- Considering the turning radius of $3 \mathrm{~m}$, using the Ackerman equation for the dimensions of our go-kart, the maximum steering angles were calculated.

- Wheelbase (L): $1220 \mathrm{~mm}$

- $\quad$ Track width (T): $863 \mathrm{~mm}$

- $\quad$ Actual Turning Radius (R): 3607.74mm

1) Outer angle: $\operatorname{Tan} A=L /(R-d / 2)$

$$
\begin{gathered}
=1220 /(3000-826 / 2) \\
\text { Tan } A=0.4715 \\
A=\operatorname{Tan}^{-1}(0.4715) \\
A=25.24
\end{gathered}
$$

2) Inner Angle: Tan $B=L /(R+d / 2)$

$$
\begin{gathered}
=1220 /(3000+826 / 2) \\
\text { Tan } \mathrm{B}=0.3574 \\
\mathrm{~B}=\operatorname{Tan}^{-1}(0.3574) \\
\mathrm{B}=19.66
\end{gathered}
$$

3) Actual Turning Radius $=\mathrm{T} / 2+\mathrm{L} \operatorname{cosec}(\mathrm{A} / 2+\mathrm{B} / 2)$ $=863 / 2+1220 \operatorname{cosec}(25.24 / 2+19.66 / 2)$

$=3628.94$

The centre to centre distances between the sleeve and steering arms are $89 \mathrm{~mm} \& 127 \mathrm{~mm}$ respectively. The angular distance covered by the steering arm is $78.23 \mathrm{~mm}$.corresponding to the inner steer angle of $35.37^{\circ}$. The same angular distance must be travelled by the sleeve and corresponding to the angular distance the sleeve should rotate by $50.52^{\circ}$, which is same the steering wheel has to be turned to rotate the inner wheel by $35.37^{\circ}$.

4) $\%$ Ackermann $=\mathrm{A}-\mathrm{B} / \mathrm{Tan} \%(1 / \tan \mathrm{B}-1)-\mathrm{B}$

$$
\begin{aligned}
& =30.69-22.73 / 31.47 \\
& =0.96 * 100 \\
& =96 \%
\end{aligned}
$$

The steering ratio is set to $1: 1$ for a quick vehicle response

No of eye bolts- 4

Length of tie rod-12.9 inches

Self manufactured steering wheel continuous shape

Height of steering column-25 inches

TABLE I RESULTS

\begin{tabular}{|c|c|}
\hline Steering system & Ackermann steering (mechanical linkages) \\
\hline Wheel base & $1220 \mathrm{~mm}$ \\
\hline Track width & $863 \mathrm{~mm}$ \\
\hline Turning radius & $3607.74 \mathrm{~mm}$ \\
\hline Steering ratio & $1: 1$ \\
\hline Inside angle & 19.66 \\
\hline Outside angle & 25.24 \\
\hline
\end{tabular}

V. ANALYSIS

Analysis on the stub axle is done by applying a force of $410 \mathrm{~N}$ in upward direction and FOS calculated is $=4.15$. 
ISO 3297:2007 Certified

Vol. 4, Issue 5, May 2017

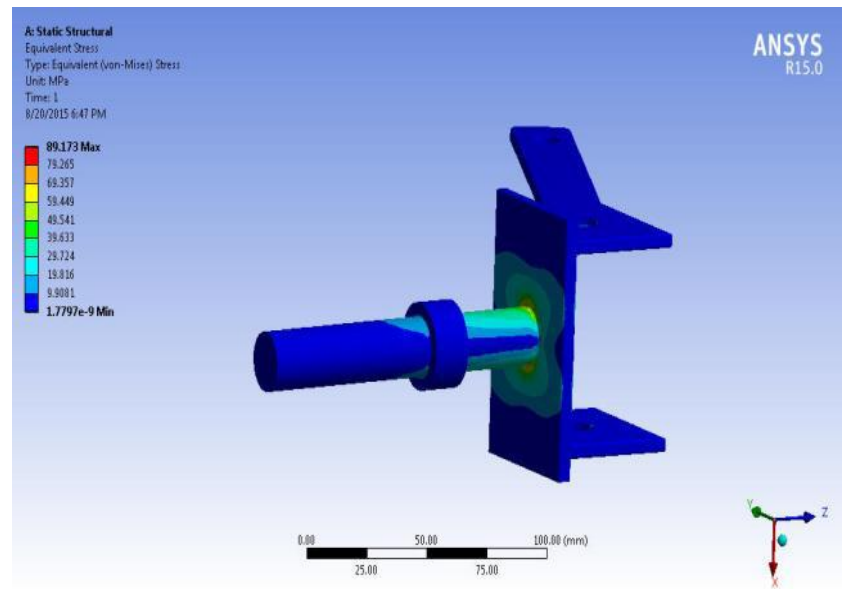

Fig.4. Stub axle analysis

\section{CONCLUSION}

The manual mechanical linkages steering system is not used in heavy weight vehicles due to high axle loads, although it is simple in design and easy to manufacture, therefore it is commonly used in light weight vehicles. The values calculated in the paper may differ practically due to steering linkages error or due to improper steering geometry, so these values are useful to understand the interdependency of the quantities on each other and to design a ideal manual mechanical linkages system for the vehicle.

\section{ACKNOWLEDGMENT}

The team expresses its sincere gratitude to Dr. Syed Azam Pasha Quadri, HOD (Mechanical) for their continuous support and encouragement. We are also thankful to our faculty advisors Mr. Mohd Anwar and Mr. Ashraf Shaik for the valuable advice and supervision.

\section{REFERENCES}

[1] R.S. Khurmi, J.K. Gupta "Theory of Machines",S. Chand\& Company Pvt. Ltd., Vol 1, 14th Edition, 2014.

[2] S.K. Gupta "A Textbook of Automobile Engineering”, S.Chand \& Company Pvt. Ltd., Vol 1, 1st Edition, 2014.

[3] Saket Bhishikar, Vatsal Gudhka, Neel Dalal, Paarth Mehta, Sunil Bhil, A.C. Mehta "Design and Simulation of 4 Wheel Steering System", International Journal of Engineering and Innovative Technology (IJEIT), Volume 3, Issue 12, June 2014.

[4] Flabel Jean Claude Practical Stress Analysis for Design Engineers

[5] Gillespie Thomas D (1992) Fundamentals Of Vehicle Dynamics: SAE 